\title{
Internal Rotation of Cyclopentadienyl Rings in Ferrocene Derivatives
}

\author{
Yutaka Okada, Shoko Yamamoto, Yoshinori Namba, Takahiro Masuda, Kazuhisa Sakamoto \\ Department of Applied Chemistry, Ritsumeikan University, Kusatsu, Japan \\ Email: ygvictor@sk.ritsumei.ac.jp
}

How to cite this paper: Okada, Y., Yamamoto, S., Namba, Y., Masuda, T. and Sakamoto, K. (2016) Internal Rotation of Cyclopentadienyl Rings in Ferrocene Derivatives. Spectral Analysis Reviews, 4, 41-48. http://dx.doi.org/10.4236/sar.2016.44004

Received: August 25, 2016

Accepted: October 17, 2016

Published: October 20, 2016

Copyright $\odot 2016$ by authors and Scientific Research Publishing Inc. This work is licensed under the Creative Commons Attribution International License (CC BY 4.0).

http://creativecommons.org/licenses/by/4.0/

\begin{abstract}
The relaxation time of several ferrocene derivatives was measured, and the internal rotation was discussed. For almost all the derivatives, the degree of the internal rotation was constant in spite of the different molecular weights. However, for (triphenylmethyl)ferrocene, the rotation of the unsubstituted ring would be slower due to the bulkiness of the substituent. Furthermore, the derivatives that have a hydroxyl- or acetyl group on the substituent were also discussed. Their rotation would be influenced by the location of these substituents.
\end{abstract}

\section{Keywords}

Ferrocene, Internal Rotation, NMR Relaxation Time, Partial Molar Volume

\section{Introduction}

One of the interesting features of ferrocenes is the rotation of the cyclopentadienyl $(\mathrm{Cp})$ ring around the $\mathrm{Cp}-\mathrm{Fe}-\mathrm{Cp}$ bond axis. On the unsubstituted ferrocene in solution, the two $\mathrm{Cp}$ rings freely rotate around the bond axis [1]. A change in the rotation property when some substituents were introduced into the $\mathrm{Cp}$ rings is very interesting.

For the 1,1'-disubstituted ferrocenes, many studies have mainly used the dipole moment measurement. The two $\mathrm{Cp}$ rings in 1,1'-diacetyl-or 1,1'-benzoylferrocene freely rotate [2]. However, the rotation is restricted in the 1,1'-dihaloferrocenes, and the cis-like conformation, where the two halogen atoms are close, is very unstable [3]. The degree becomes greater according to the size of the halogen atoms. These results for the 1,1'-dihaloferrocenes were due to the electrostatic effect between the two halogen atoms. 
The authors reported the $\mathrm{Cp}$ ring rotation on the following derivatives. The Cp rings of 1,1'-dit-butylferrocene freely rotate, but the rings of 1,1'-bis(triphenylmethyl)ferrocene having bulky substituents were restricted, and the cis-like conformation was very unstable [4].

On the other hand, a study of the monosubstituted ferrocenes was done by a longitudinal relaxation time NMR method instead of the dipolar moment [5]. In this study, the ${ }^{1} \mathrm{H}$ - and ${ }^{13} \mathrm{C}-\mathrm{NMR}$ relaxation time was measured. The rotation of the $\mathrm{Cp}$ rings was discussed by comparing the substituted and unsubstituted $\mathrm{Cp}$ rings.

\section{Experimental}

\subsection{Synthesis}

The ferrocene derivatives used in this study were synthesized by well-known methods [4] [6] [7] [8]. The compounds were identified by $1 \mathrm{H}$ NMR, IR, and mass spectra as described in the previous paper [4] [6]. The synthetic routes were shown in Scheme 1.

\subsection{Measurement of Relaxation Time}

The longitudinal relaxation time was measured using JEOL A-400 and ECS-400 spectrometers.NMR samples consisted of $0.5 \mathrm{ml}$ of solution in $5 \mathrm{~mm}$ o.d. tubes. After degassing by passing Ar gas, the spectra were recorded at ambient temperature. Longitudinal relaxation times values were measured under proton-noisedecoupling conditions by the inversion recovery method.

\subsection{Measurement of Partial Molar Volume}

The partial molar volumes were measured using a Lipkin-Devison type pycnometer. The ferrocene derivatives were dissolved in benzene, and the solution was

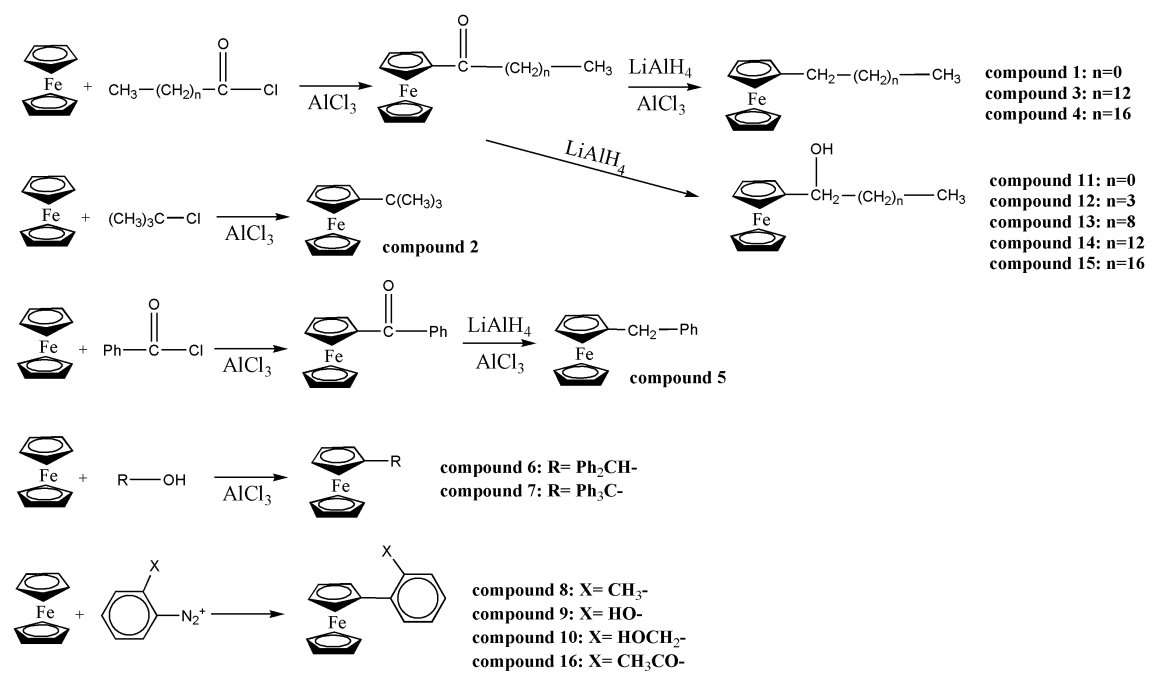

Scheme 1. Synthetic routes of the ferrocene derivatives. 
added in the pycnometer. The concentration of the solutions was $0.5-3.0 \mathrm{wt} \%$. The pycnometer was sintered in a thermostatic tank at $30^{\circ} \mathrm{C}$, and the volume of solution were measured. From this volume and weight of the solution, the partial molar volumes were calculated.

\section{Results and Discussion}

The relaxation time is a parameter for the mobility of molecule or its part. The ferrocene $\mathrm{Cp}$ rings rotate around the $\mathrm{Cp}-\mathrm{Fe}-\mathrm{Cp}$ bond axis. The $\mathrm{Cp}$ carbon relaxation times are influenced by the degree of the $\mathrm{Cp}$ ring mobility. However, the degree contains several mobility modes; rotation, vibration, translation, and so on. For discussion of the internal rotation, the relaxation times of the two $\mathrm{Cp}$ rings must be compared.

For comparing the substituted and unsubstituted $\mathrm{Cp}$ rings, the values of the 1 '- and $\beta$-positions were used. Because the 1'-position carbon on the unsubstituted $\mathrm{Cp}$ ring has hydrogen atoms on both side carbons, the $\beta$-position carbon on the substituted $\mathrm{Cp}$ ring is similar.

The longitudinal relaxation time of the $\mathrm{Cp}$ group carbon is summarized in Table 1. The partial molar volumes are listed in Table 2.

Table $1 .{ }^{13} \mathrm{C}$ longitudinal relaxation time of ferrocene derivatives ${ }^{\mathrm{a}, \mathrm{b}}$.

\begin{tabular}{|c|c|c|c|c|c|}
\hline \multirow{2}{*}{ Compound } & \multirow{2}{*}{ Substituent } & \multicolumn{3}{|c|}{ Longitudinal relaxation time (T1)/s } & \multirow{2}{*}{$1^{\prime} / \beta$} \\
\hline & & $1^{\prime}$ & $\alpha$ & $\beta$ & \\
\hline 1 & ethyl & 14.50 & 10.30 & 10.70 & 1.36 \\
\hline 2 & $t$-butyl & 13.50 & 8.58 & 9.06 & 1.49 \\
\hline 3 & pentadecyl & 6.14 & 3.72 & 3.87 & 1.59 \\
\hline 4 & octadecyl & 5.23 & 3.13 & 3.55 & 1.47 \\
\hline 5 & benzyl & 9.91 & - & 6.84 & 1.45 \\
\hline 6 & diphenylmethyl & 6.38 & 4.60 & 4.69 & 1.36 \\
\hline 7 & triphenylmethyl & 6.97 & 3.12 & 3.12 & 2.23 \\
\hline 8 & $o$-methylphenyl & 8.44 & 5.59 & 5.78 & 1.46 \\
\hline 9 & $o$-hydroxyphenyl & 5.66 & 2.83 & 4.24 & 1.33 \\
\hline 10 & $o$-(hydroxymethyl)phenyl & 7.08 & 3.03 & 3.86 & 1.83 \\
\hline 11 & 1-hydroxyethyl & 9.51 & 7.21 & 7.59 & 1.25 \\
\hline 12 & 1-hydroxypentyl & 7.13 & 3.35 & 4.26 & 1.67 \\
\hline 13 & 1-hydroxydecyl & 7.32 & 3.61 & 4.61 & 1.59 \\
\hline 14 & 1-hydroxypentadecyl & 6.11 & 2.89 & 4.00 & 1.53 \\
\hline 15 & 1-hydroxybenzyl & 6.46 & - & 3.31 & 1.95 \\
\hline
\end{tabular}

${ }^{\mathrm{a} S o l v e n t: ~ b e n z e n e, ~}{ }^{\mathrm{b}} \mathrm{Temperature:} \mathrm{ambient.}$ 
Table 2. Partial molar volume of ferrocene derivatives ${ }^{\mathrm{a}, \mathrm{b}}$.

\begin{tabular}{ccc}
\hline \multirow{2}{*}{ Compound } & Substituent & Partial molar volume $/ \mathrm{cm}^{3} / \mathrm{mol}$ \\
\cline { 2 - 3 } 2 & ethyl & 66.7 \\
\hline 3 & t-butyl & 62.5 \\
4 & pentadecyl & 64.0 \\
5 & octadecyl & 61.7 \\
6 & benzyl & 89.7 \\
7 & diphenylmethyl & 93.0 \\
8 & triphenylmethyl & 111.3 \\
9 & $o-$-methylphenyl & 91.5 \\
10 & $o$-hydroxyphenyl & 122.3 \\
11 & $o-($ hydroxymethyl)phenyl & 115.4 \\
12 & 1-hydroxyethyl & 94.7 \\
13 & 1-hydroxypentyl & 94.6 \\
14 & 1-hydroxydecyl & 82.3 \\
15 & 1-hydroxypentadecyl & 73.6 \\
\hline
\end{tabular}

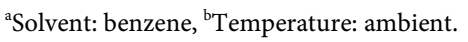

\subsection{Alkyl- and Arylferrocenes}

The relationship between the molecular weight and $1^{\prime} / \beta$ value is shown in Figure 1. (o-Methylphenyl)ferrocene and benzylferrocene are isomers (molecular weight 276), and their $1^{\prime} / \beta$ values were almost equal (Table 1 Compounds 5 and 8 ). This shows that the kind of substituent does not affect the rotation properties. The $1^{\prime} / \beta$ values of almost all the derivatives containing these two derivatives were about 1.5. However, for (triphenylmethyl)ferrocene, the $1^{\prime} / \beta$ value was higher (Figure 1). Based on this result, the unsubstituted $\mathrm{Cp}$ ring of this derivative would rotate faster than the rings of the other derivatives.

The relationship between the molecular weight and the partial molar volume is indicated in Figure 2. In this figure, the derivatives were classified into three groups. The first group is the alkylferrocenes, and the partial molar volumes are about 65 (Figure 2). The second group is the derivatives having phenyl groups, and their values are about 90 (Figure 2). The last one is (triphenylmethyl)ferrocene, and its value is 110 (Figure 2). This classification shows that the derivatives possessing phenyl group(s) have larger volumes than the derivatives possessing no phenyl group. Especially the (triphenylmethyl)ferrocene's volume is significantly large.

These results would be interpreted as follows. The bulky triphenylmethyl group exists to hang over unsubstituted $\mathrm{Cp}$ ring protons. As a result, the space in which the solvent is difficult to approach is produced (Figure 3 ). Therefore, the 


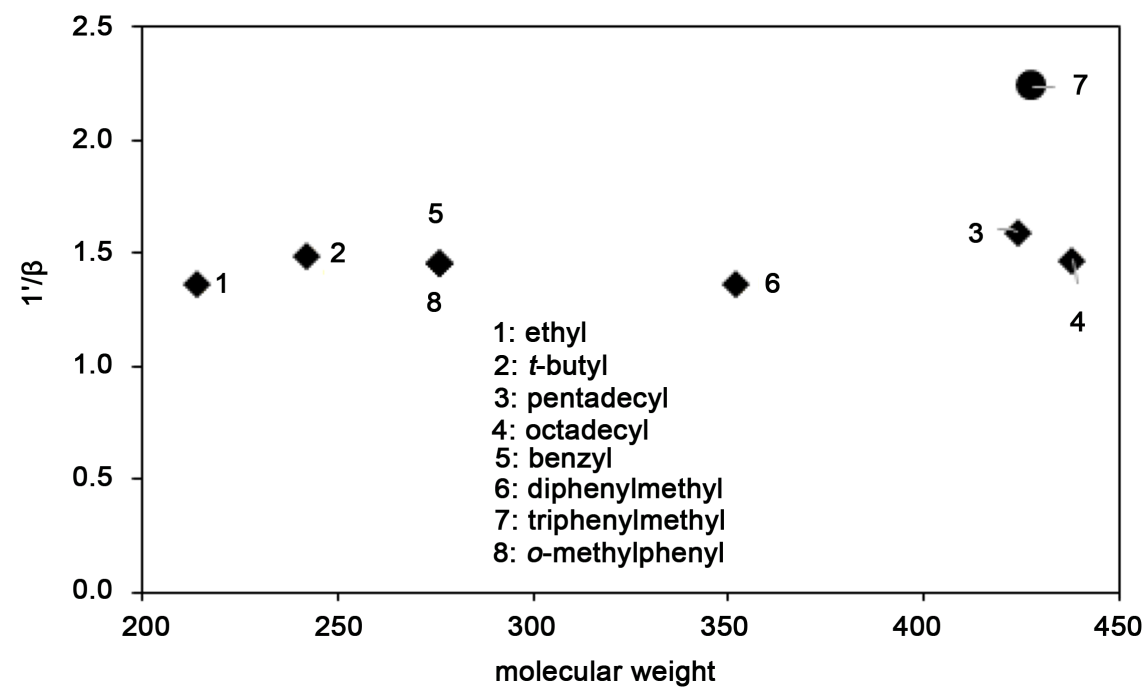

Figure 1 . The relationship between the molecular weight and $1^{\prime} / \beta$ value on alkyl- and arylferrocenes.

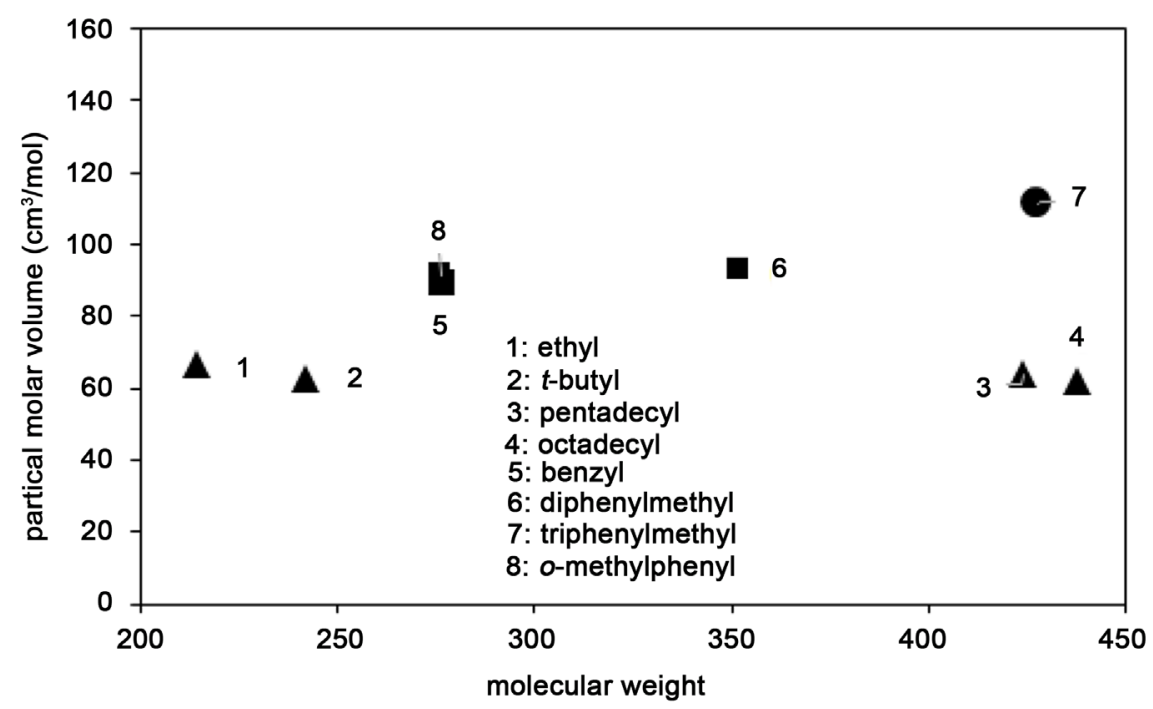

Figure 2. The relationship between the molecular weight and the partial molar volume on alkyl- and arylferrocenes.

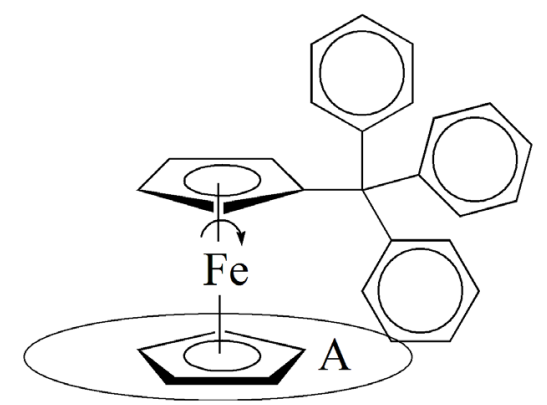

Figure 3. The space (A) in which the solvent is difficult to approach on (triphenylmethyl)ferrocene. 
rotation of the Cp group is not prevented by the solvent, thus the $1^{\prime} / \beta$ value becomes high. For diphenylmethyl group, a conformation in which the phenyl groups do not exist near the unsubstituted $\mathrm{Cp}$ proton is possible by the rotation around $\mathrm{Cp}-\mathrm{Ph}$ bond axis. Such a conformation would result in the smaller $1^{\prime} / \beta$ value and middle partial molar volume (Figure 2).

\subsection{Ferrocene Derivatives Having AHydroxyl Group}

For the alkyl- and arylferrocenes, the $1^{\prime} / \beta$ value was mostly fixed except for (triphenylmethyl)ferrocene (Figure 4). Of the ferrocene derivatives having a hydroxyl group, only (1-hydroxybenzyl)ferrocene showed a high value (Table 1 Compound 15). Furthermore, the derivative has a largerpartial molar volume than the other derivatives (Figure 5). In (1-hydroxybenzyl)ferrocene, the benzene ring is twisted by the formation of the $\mathrm{OH}-\pi$ type hydrogen bond [9] Therefore, the substituent would produce a space in which the solvent is difficult to approach. On the other hand, (1-hydroxyalkyl)ferrocene has no such hydrogen bond, thus it would have similar values for $1^{\prime} / \beta$ and the partial molar volume.

When (o-hydroxyphenyl)ferrocene and [o-(hydroxymethyl)phenyl]ferrocene were compared, the former showed a low $1^{\prime} / \beta$ value. In (o-hydroxyphenyl)ferrocene, a strong $\mathrm{OH}-\mathrm{d}$ type hydrogen bond is formed, so that the hydroxyl group exists near the unsubstituted $\mathrm{Cp}$ ring [6]. Therefore, the rotation of the $\mathrm{Cp}$ ring would be disturbed. On the other hand, [o-(hydroxymethyl)phenyl]ferrocene does not have such a hydrogen bond, because the hydroxyl group and iron atom are too close.

\section{3. (o-Acetylphenyl)Ferrocene}

As mentioned in a previous paper [10], (o-acetylphenyl)ferrocene has a chelate

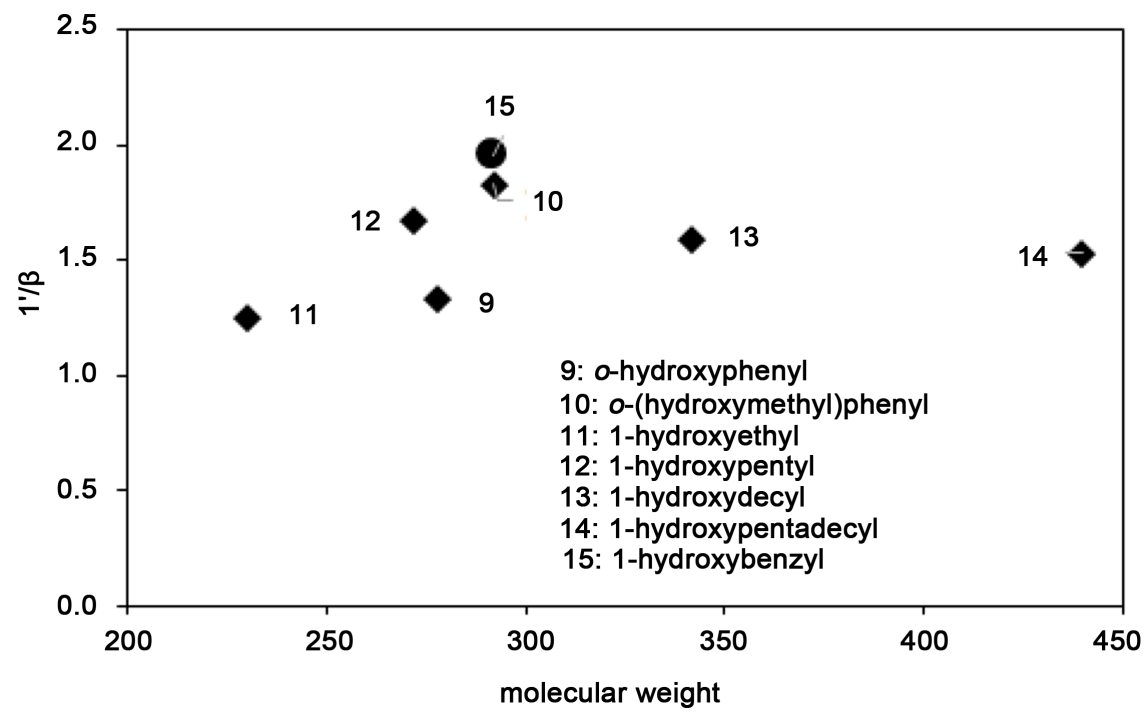

Figure 4. The relationship between the molecular weight and $1^{\prime} / \beta$ value on ferrocenes derivatives having a hydroxyl group. 
structure in which a metal cationis incorporated between the carbonyl oxygen and iron atom. In this section, the effect on the relaxation time by such a chelate ring formation is discussed. Here, acetonitrile- $\mathrm{d}_{3}$ was employed as the solvent to dissolve the metal salts, but the solubility is low. Therefore, the ${ }^{1} \mathrm{H}$ relaxation time was used for the following discussion. The longitudinal relaxation time of the Cp group proton is summarized in Table 3.

(o-Acetylphenyl)ferrocene alone showed a $1.771^{\prime} / \beta$ value. In the presence of $\mathrm{Ca}^{2+}$, which does not form a strong chelate, the value did not significantly change. However, $\mathrm{Al}^{3+}$ forming a strong chelate structure (Figure 6) reduces the $1^{\prime} / \beta$ value. These results would be due to the chelate structure in which the metal cation and carbonyl oxygen exist in the neighborhood of the unsubstituted $\mathrm{Cp}$ group. Therefore, the $\mathrm{Cp}$ ring rotation would be prevented in a manner similar to that for the (o-hydroxyphenyl)ferrocene mentioned in Section 3.2.

\section{Conclusion}

By comparing the relaxation time of substituted and unsubstituted $\mathrm{Cp}$ rings, the internal rotation of substituted ferrocenes was discussed. For almost all the

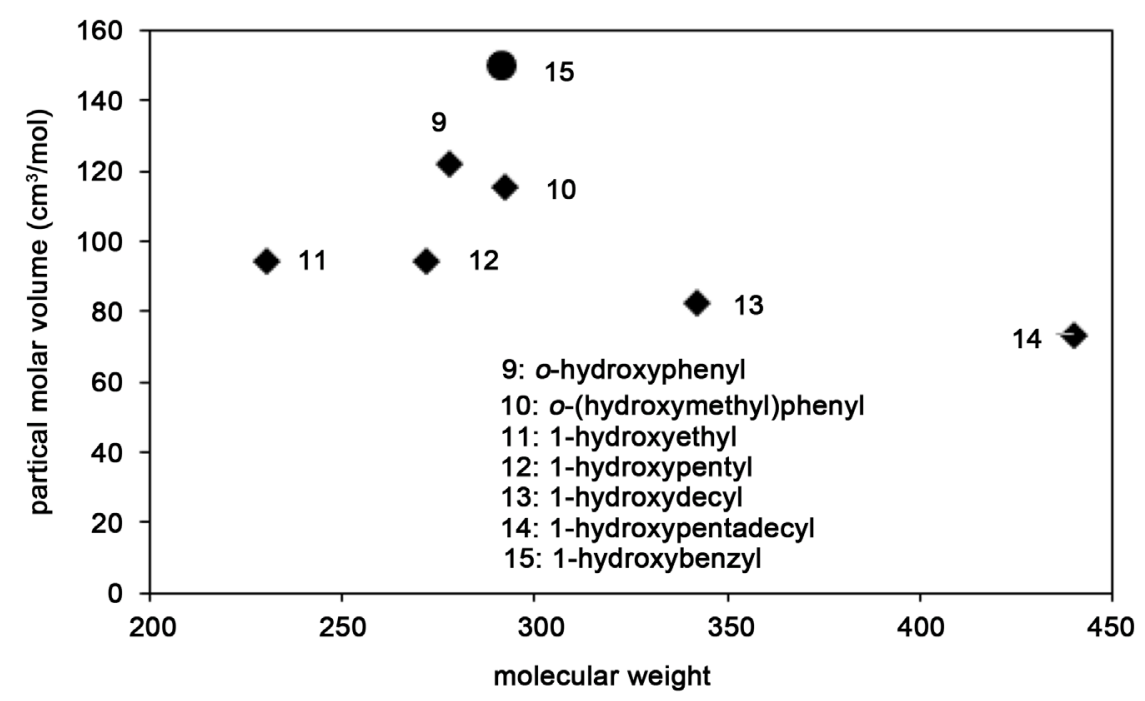

Figure 5. The relationship between the molecular weight and the partial molar volume on ferrocenes derivatives having a hydroxyl group.

Table $3 .{ }^{1} \mathrm{H}$ longitudinal relaxation time of (o-acetylphenyl)ferrocene (16) in the absence metal ions.,

\begin{tabular}{ccccc}
\hline \multirow{2}{*}{ Entry } & Metal ion & \multicolumn{2}{c}{ Longitudinal relaxation time $(\mathrm{T} 1) / \mathrm{s}$} & \multirow{2}{*}{$1^{\prime} / \beta$} \\
\cline { 3 - 4 } & & $1^{\prime}$ & $\beta$ & \\
\hline 1 & none & 6.97 & 3.93 & 1.77 \\
2 & $\mathrm{Ca}^{2+}$ & 4.72 & 2.55 & 1.85 \\
3 & $\mathrm{Al}^{3+}$ & 3.36 & 2.54 & 1.32 \\
\hline
\end{tabular}

${ }^{\text {a }}$ Solvent: acetonitrile- $\mathrm{d}_{3}$, ${ }^{\mathrm{b}}$ Temperature: ambient. 


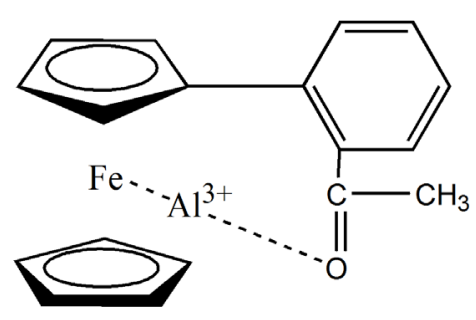

Figure 6. Plausible coordination of (o-acetylphenyl)ferrocene with $\mathrm{Al}^{3+}[10]$.

derivatives, the degree of the internal rotation was constant in spite of the different molecular weights. However, for (triphenylmethyl)ferrocene, the rotation of the unsubstituted ring would be slower. Furthermore, such a slow internal rotation is found for some derivatives that have a hydroxyl- or acetyl group on the substituent. These slow rotations would result in the existence of space in which the solvent is difficult to approach.

\section{References}

[1] Astruc, D. and Dabard, R. (1979) Energy Barrier to Internal Rotation in Some Ferrocene Derivatives from Dielectric Measurements. Journal of Organometallic Chemistry, 179, 205-213. https://doi.org/10.1016/S0022-328X(00)95223-9

[2] Sorriso, S. and Lumbroso, H. (1970) Conformations of 1,1'-diacetyl- and 1,1'-Dibenzoylferrocenes. Tetrahedron, 26, 2695-2701. https://doi.org/10.1016/S0040-4020(01)92844-3

[3] Sorriso, S., Cardaci, G. and Murgia, S.M. (1972) Dipole Moments and Internal Rotation in 1,1'-Dihaloferrocenes. Journal of Organometallic Chemistry, 44, 181-184. https://doi.org/10.1016/0022-328X(72)80052-4

[4] Okada, Y., Nakai, N., Nakamura, N. and Hayashi, T. (1987) The Influences of Bulky Substituents on the Conformations and Proton and Carbon-13 NMR Chemical Shifts of Ferrocene Derivatives. Nippon Kagaku Kaishi, 1567-1572. https://doi.org/10.1246/nikkashi.1987.1567

[5] Arimura, T. and Ide, S. (2004) ${ }^{1} \mathrm{H}$ NMR Relaxation Time Studies of Molecular Motions in a 1,3-Alternate-Shaped Calix[4] arene Ensemble. Journal of Oleo Science, 5, 275-278. https://doi.org/10.5650/jos.53.275

[6] Hayashi, T. and Okada, Y. (1987) A Conformational Study of (Substituted Phenyl)ferrocenes by the Method of Proton NMR. Nippon Kagaku Kaishi, 208-214. https://doi.org/10.1246/nikkashi.1987.208

[7] Broadhead, G.D. and Pauson, P.L. (1955) Ferrocene Derivatives. II. Arylation. Journal of the Chemical Society, 367-370. https://doi.org/10.1039/jr9550000367

[8] Leigh, T. (1964) Ferrocene Derivatives Containing Tertiary Alkyl Groups. Synthesis by the Friedel-Crafts and Other Methods. Journal of the Chemical Society, 32943302. https://doi.org/10.1039/JR9640003294

[9] Baker, A.W. and Bublitz, D.E. (1966) Enthalpies of Intramolecular Interactions in Ferrocenylalcohols. Spectrochimica Acta, 22, 1787-1799. https://doi.org/10.1016/0371-1951(66)80223-0

[10] Yamamoto, S. and Okada, Y. (In Press) The Interaction between (o-Acetylphenyl)ferrocene and Metal Ions. Organic Communications. 
Submit or recommend next manuscript to SCIRP and we will provide best service for you:

Accepting pre-submission inquiries through Email, Facebook, LinkedIn, Twitter, etc. A wide selection of journals (inclusive of 9 subjects, more than 200 journals)

Providing 24-hour high-quality service

User-friendly online submission system

Fair and swift peer-review system

Efficient typesetting and proofreading procedure

Display of the result of downloads and visits, as well as the number of cited articles Maximum dissemination of your research work

Submit your manuscript at: http://papersubmission.scirp.org/

Or contact sar@scirp.org 